\title{
Gel aloe vera reduces MMP-9 in diabetic wounds
}

\author{
Yunita Sari ${ }^{1 *}$, Iwan Purnawan ${ }^{1}$, Dhadhang Wahyu Kurniawan ${ }^{2}$, and Eman Sutrisna ${ }^{3}$ \\ ${ }^{1 *}$ Department of Nursing, Universitas Jenderal Soedirman, Purwokerto, Indonesia \\ 2. Department of Pharmaceutical Science, Universitas Jenderal Soedirman, Purwokerto, Indonesia \\ ${ }^{3 .}$ Department of Medical Science, Universitas Jenderal Soedirman, Purwokerto, Indonesia.
}

\begin{abstract}
Gel aloe vera (GAV) is a good candidate for wound treatment for fisheries, since it is cheap, could be grown in coastal areas, and could reduce inflammation, infection and improve reepithelialization in diabetic wound. However, the effect of GAV on reducing matrix metalloproteinase (MMP)-9 is still unknown. High level of MMP-9 is one of the reasons why diabetic wounds frequently fail to heal. Abundant level of MMP-9 will cause degradation of collagen formation. Therefore, the purpose of this study was to investigate the effects of GAV on reducing MMP-9. The induction of diabetes was conducted by using Alloxan Monohydrate. The rats were divided into two groups, GAV group, and control group. The wound appearance, exudate, intensity of fibroblast, and intensity of MMP9 were compared. Mann-Whitney U test was used to analyze the difference in the intensity of positive cells for MMP-9. The study showed that the wound appearance in the GAV group was smaller compared with control group. In the GAV group, the intensity of positive cells for MMP-9 was significantly lower than in the control group. This study showed that GAV could reduce MMP-9, and therefore GAV could be recommended for wound treatment for patients with diabetic wound.
\end{abstract}

\section{Introduction}

Diabetes mellitus (DM) is the condition when the blood sugar above the normal range. The number of patients with DM is increased worldwide. The number of patients with DM in 1980 was about 108 million, and rise becomes 422 million in 2014 [1]. Previous studies showed that the prevalence of DM is higher in the coastal region than other areas [2-3]. The high prevalence of DM in the coastal region among fisheries might occur due to unhealthy lifestyle [3]. In Indonesia, the exact of the number of patients with DM is still unknown, however, the proportion of people with DM among fisheries in Indonesia is high compared with other jobs [4].

The higher number of DM in the coastal regions needs serious attention since the rise of the number of DM also will be followed with a high number of DM complication. One of the complications that most frequently to occur in the DM patients is diabetic wound [5]. Although no study that reported the number of diabetic wounds in the coastal region, however, based on the high prevalence of DM cases in the coastal area, it can be predicted

Corresponding author: $\underline{\text { sasa.yunita@gmail.com }}$

(C) The Authors, published by EDP Sciences. This is an open access article distributed under the terms of the Creative Commons Attribution License 4.0 (http://creativecommons.org/licenses/by/4.0/). 
that the number of diabetic wounds is also high in the coastal region. Moreover, fisheries are susceptible to get wound [6]. Previous study showed that fisherman is susceptible to suffer from suppurative skin lesions due to working on trawlers in the coastal regions [6]. They are also easy to get wound in the marine environment due to coral cut, injury by a knife when filleting the fish, or by penetrating by a hook [6].

Diabetic wound is difficult to treat since it is usually easy to get infected and contain a high level of MMP-9. The bacteria that most frequently present in the wound of fisheries is Staphylococcus aureus [6]. Therefore, fisheries need topical therapy that can reduce wound infection, especially by Staphylococcus aureus. The study by Banu, Sathyanarayana, \& Chattannavar (2012) showed that gel aloe vera (GAV) could reduce wound infection by Staphylococcus aureus [7], and therefore, GAV can be a good candidate for wound treatment for fisheries. In addition, aloe vera is cheap, easy to get and can be grown in the coastal region. However, up to present the role of aloe vera in reducing MMP-9 is still unknown.

Gel Aloe vera also has been used for many health purposes since it contains anti laxative agent, antitumor and antiviral agent, antiseptic agent, and anti-aging agent [8]. It is even reported that GAV can also reduce inflammation, infection, and blood glucose level [9]. Many studies have been conducted to assess the effect of GAV on wound healing, either acute wound or diabetic wounds [10-12]. In diabetic wounds, our previous study also showed that GAV could reduce inflammatory cells, and improve the migration of epithelial cells in diabetic wound [12]. We also investigated the effect of different concentration of aloe vera, and we found that Aloe vera $30 \%$ as good as fresh aloe vera in reducing inflammation [13].

As above mentioned, one of the reasons for the failure of healing in the diabetic wound is a high level of matrix metalloproteinases (MMPs) [14]. Although GAV can reduce inflammatory cells and improve reepithelialization, the effect of GAV in reducing MMP-9 in diabetic wound is unknown. Up to the present, no study that investigates the effect of GAV in reducing MMP-9 in diabetic wounds. The study about GAV and MMP-9 is only conducted in in vitro study using peripheral mononucleated cells [15].

There are many types of MMPs during wound healing, they are MMPs-1, MMP-2, MMP-3, MMP-7, MMP-8, MMP-9, MMP-10, MMP-11, MMP-13, MMP-14, MMP-15, MMP-16, MMP-17, MMP-19, MMP-21, MMP-23, MMP-24, MMP-25, MMP-26. MMP18, MT1-MMP, MT2-MMP, MT3-MMP [16]. A study by Liu et.al (2009) showed that the main MMPs that mostly present in diabetic wound is MMP-9 [17]. Previous study using human subject revealed that the level of MMP-9 could predict the delayed healing in diabetic wound. The excessive level of MMP-9 will cause excessive degradation of collagen, and therefore the granulation tissue formation and reepithelialization will be impaired [18]. Impairment of granulation tissue and reepithelialization will cause a delay in the proliferation phase, resulting in delayed wound healing. Since the high level of MMP-9 can delay wound healing, it is needed to treat a wound with topical therapies that can reduce the level of MMP-9.

It is important to assess the effect of GAV on the level of MMPs. If GAV has an effect on reducing MMP-9, it will provide substantial evidence about the use of GAV for wound care treatment. Therefore, the purpose of this study was to investigate the effect of GAV on reducing MMP-9. 


\section{Method}

\subsection{Animal}

The animal used in this study was male Wistar rats at the age of 12-14 weeks old. The rats were bought from Universitas Muhammadiyah Purwokerto. The animal in the cage has free access to food and water. The induction of hyperglycemic rats was conducted by injecting with alloxan monohydrate. The rats were confirmed as diabetic rats if the blood glucose reaches a value of $200 \mathrm{mg} / \mathrm{dl}$ or above.

\subsection{Wounding procedure and treatment}

The rats were divided into GAV treated group and control group. In this study, we used inner gel aloe vera. The aloe vera was cut and cleaned, and the inner part of GAV was used. Control group received gel that did not contain aloe vera (sodium alginate gel). The making of the sodium alginate gel was based on previous study [13]. Each of groups consisted of 5 rats. The protocols used in the study was approved by ethical research committee, Universitas Jenderal soedirman, Indonesia.

After shaving the rats, one-centimeter of a wound was created in the right side of the abdominal region of the rats. After wounding, the wound was cleansed in both groups by using normal saline $0,9 \%$. After cleansing, the rats in the GAV group was given GAV while in the control group was given sodium alginat gel. The gel was applied by swabbing method using cotton bud. Finally, both control and GAV group were covered by parafilm dressing, followed by gauze dressing. The wounds were daily observed and photographed for twelve days.

\subsection{Tissue staining}

Hematoxylin and Eosin staining was conducted to assess tissue damage and fibroblast intensity in the skin tissue. The method of tissue processing was based on previous study [12]. The difference in the fibroblast level was assessed based on the previous study [19].

\subsection{Immunohistochemistry}

To investigate the intensity level of MMP-9, immunohistochemistry method was used. Polylysine-coated slides was used to place the serial section. The tissue was then deparaffinized and rehydrated through serial graded of ethanol and xylene. To inactivate the endogenous peroxidase, the slide was incubated for 30 minutes in 3\% hydrogen peroxide. Antigen retrieval was carried out by immersed in citrate buffer $(\mathrm{pH}$ 6.0) for $15 \mathrm{~min}$. The tissue were incubated with primary antibody. The primary antibody used in this study was monoclonal antibody against rat MMP-9 (Abcam, Cambridge, UK) with a dilution of 1:100 The section was then incubated in the biotin-conjugated secondary antibody. In this study, we used streptavidin-peroxidase to visualize the staining. We then used diaminobenzidine (DAB; Sigma, St. Louis, MO, USA) to function as the chromogenic agents and hematoxylin as the counterstaining agent. The images were magnified under a light microscope and recorded on a computer. The difference in the level of positive cells for MMP-9 was assessed using the formula HSCORE. The intensity of labeling were classified as 1,2 , or 3 (weak, moderate, or strong, respectively) [20]. 


\subsection{Statistical analysis}

The comparison of body weight and blood glucose level between treatment and control groups were analyzed by independent T-test, while the intensity of fibroblast and intensity of MMP-9 was analyzed by Mann-Whitney U-tests. The p-value less than 0,05 was considered significant. The statistical analysis was conducted by using SPSS version of 20 .

\section{Result and Disscusion}

\subsection{Body weight of rats}

The average of the body weight of the rats in the GAV group was $190 \pm 7$ Gram, while the body weight of rats in the control group was $192.5 \pm 5$ Gram. The result of independent T-test showed that there is that there is no difference in the body weight of the rats in theGAV group and in the control group.

Table 1. The body weight of GAV and control groups

\begin{tabular}{|c|c|c|}
\hline Groups & $\begin{array}{c}\text { Body weight } \\
\text { (Gram) }\end{array}$ & p-value \\
\hline Gel aloe vera & $190 \pm 7$ & 0,620 \\
\hline Control & $192.5 \pm 5$ & \\
\hline
\end{tabular}

Data as mean $\pm \mathrm{SD}$

\subsection{Blood glucose injection}

The blood glucose after injection of alloxan monohydrate in the GAV group and control group was shown in table 2. The mean of the blood glucose in the GAV group 248.75 \pm 27.7 $\mathrm{mg} / \mathrm{dl}$, and in the control group was $236.75 \pm 21.17 \mathrm{mg} / \mathrm{dl}$. Table 2 showed that the blood glucose level after injection of alloxan monohydrate was increased above $200 \mathrm{mg} / \mathrm{dl}$. Independent T-test showed that there is no significant difference in the blood glucose between two groups.

Table 2. Blood glucose in GAV and control groups

\begin{tabular}{|c|c|c|}
\hline Groups & $\begin{array}{c}\text { Blood glucose } \\
(\mathrm{mg} / \mathrm{dl})\end{array}$ & p-value \\
\hline GAV & $248.75 \pm 27.7$ & 0,519 \\
\hline Control & $236.75 \pm 21.17$ & \\
\hline
\end{tabular}




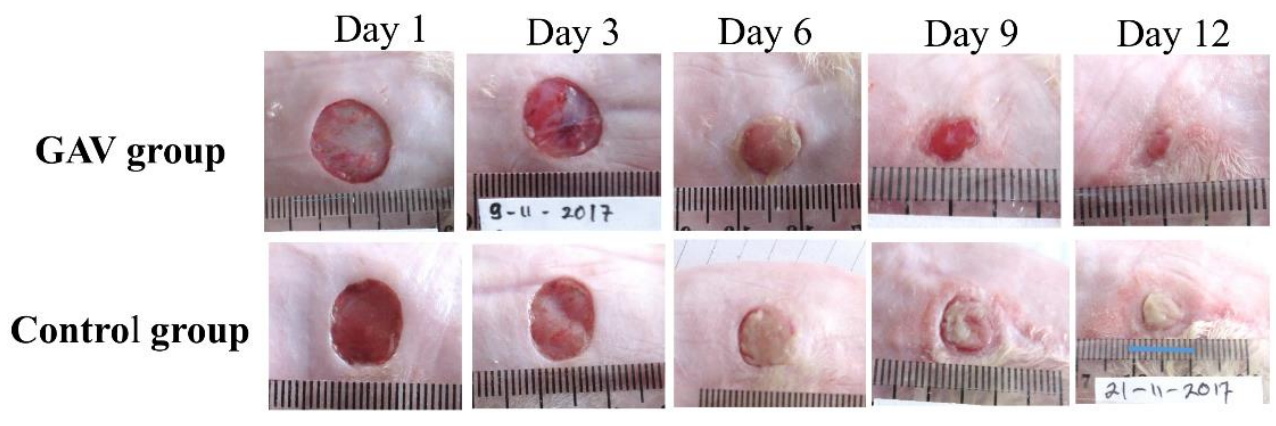

Fig 1. Wound appearance between GAV group and control group

\subsection{Wound appearance}

The wound appearance can be seen in Figure 1. Figure 1 showed that the appearance of wound on day 1 to day 3 was same between GAV group and control group. There is no necrotic tissue in two groups. In addition, the exudate was still clear in color in both groups. On day 6, the wound in both groups was covered with necrotic tissue. However, the exudate in control group was purulent compared with the exudate in the GAV group. On day 9, the wound in the GAV group was covered with granulation tissue that has a color of red, and the wound size was smaller compared with day 6. Comparing with control, the wound in the control group on day 6 was still covered with necrotic tissue. The necrotic tissue in the control group was thicker on day 9 compared with day 6 . The wound size in the control group was almost same compared with on day 9. The exudate in the GAV group was clear in color, while exudate in the control group was purulent. On day 12, the wound size in the GAV group was smaller compared with on day 9. The wound size in the GAV group was also smaller compared with wound size in the control group. Moreover, the wound bed in the control group was still covered with necrotic tissue.

\subsection{Intensity of fibroblast}

The intensity of the fibroblast in the GAV group was more pronounced compared with control group. Most fibroblast located in the upper part of dermis layer. The difference in the level of fibroblast was shown in table 3.

Table 3. The difference in the fibroblast level

\begin{tabular}{|c|c|c|}
\hline Groups & Fibroblast & p-value \\
\hline GAV & $4^{*}$ & 0.04 \\
\hline Control & 3 & \\
\hline
\end{tabular}

Rating scale: $0=$ absent, $1=$ occasional, $2=$ moderate, $3=$ abundant, $4=$ very abundant $* \mathrm{p}<0.05$ 


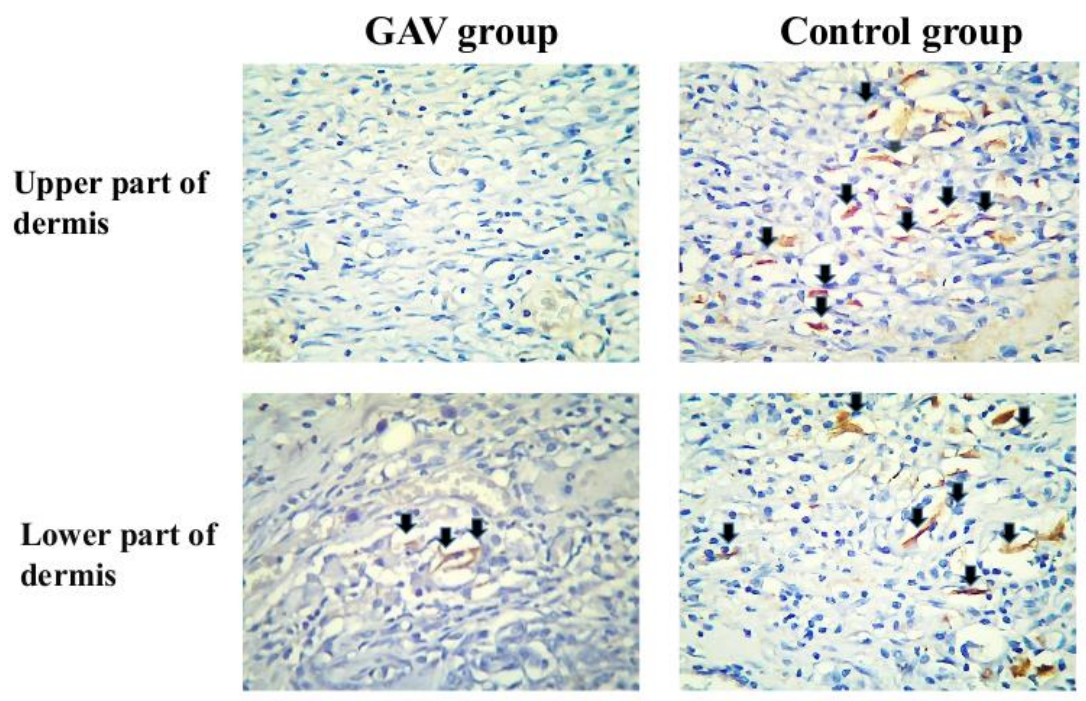

Fig 2. The MMP-9 positive cells (arrow) between GAV and control groups in the upper part of dermis (below epidermis) and lower part of dermis (magnification of 400 times)

The result of MMP-9 staining is shown in figure 2. The blue color means the nucleus cell, while the brown color indicates the positive cells for MMP-9. Figure 2 showed that the positive cells for MMP-9 was more pronounced in the control group compared with the GAV group. The positive cells for MMP-9 were pronounced in the control group, not only in the upper part of the dermis, but also in the lower part of the dermis. The comparison of the intensity of MMP-9 in the dermis layer between GAV group and control group was seen in table 4. From table 4, it could be seen that the intensity of MMP-9 in the GAV group was significantly less than in the control group $(\mathrm{P}=0,011)$.

Table 4. The intensity of MMP-9 in both groups

\begin{tabular}{|c|c|c|}
\hline Groups & Intensity of MMP-9 & p-value \\
\hline GAV & $1^{*}$ & 0.011 \\
\hline Control & 3 & \\
\hline
\end{tabular}

Values indicated median score

Rating scale: 1 = weak, 2 = moderate, 3 = strong $* p<0.05$

This study is the first study to investigate the role of GAV in reducing MMP-9 in diabetic wound. This study will provide the clinical importance of gel aloe vera in the treatment of diabetic wound. Our study revealed that GAV could reduce MMP-9.

The previous study showed that MMPs have an important role in morphogenesis, wound healing and tissue repair following injury [21]. However, when the MMPs is dysregulated, it can cause many diseases and disorders such as stenosis, heart failure, cancer, arthritis, encephalomyelitis, etc [21]. During wound healing process, MMPs can clean the debris, bacteria, and broken extracellular matrix during early phase of wound healing [16]. It also has a role and affects the differentiation, migration of epithelial, angiogenesis, and apoptosis process [22]. The MMP activity was strictly regulated by the presence of tissue inhibitors of metalloproteinase (TIMP) [23]. The balance between MMP and TIMP will make wound healing progress well. However, the increase of MMPs level will cause excessive degradation of collagen. 
There are many MMPs have been studied so far. They are MMPs-1, MMP-2, MMP-3, MMP-7, MMP-8, MMP-9, MMP-10, MMP-11 and MMP-13, MMP-14, MMP-15, MMP16, МMP-17, ММР-19, МMP-21, МMP-23, МMP-24, МMP-25, МMP-26. МMP-18, MT1-MMP, MT2-MMP, MT3-MMP, etc. [16]. Among these MMPs, the MMP that is highly present in the diabetic wound is MMP-9 [24]. The reason why MMP-9 is at a high level in the diabetic wound is unclear. Previous study showed that inflammatory cells are increased in the diabetic wound compared with acute wound [25]. The inflammatory cells such as neutrophil and macrophage will release MMP-9. It might the reason why the MMP9 is high in the diabetic wound compared with acute wound [26]. Further study is needed to confirm the cause of the increase of MMP-9 in the diabetic wound. In the macroscopical findings, the formation of granulation tissue in the control group is low. The wound bed is also covered with necrotic tissue on day 9 when the wound bed in the GAV group was fully covered with granulation tissue. The lacking of the granulation tissue in the control group might because the high level of MMP-9 as seen in the result of immunohistochemistry. The increased level of MMP-9 might cause prolonged inflammation phase, resulting in the failure of proliferation phase. In our study, the exudate in the control group on day 9 is also purulent compared with the exudate in the GAV group, which is clear and did not contain necrotic tissue. Wound exudates is a wound fluid that is produced during wound healing. The color of exudate reflects the microenvironment of a wound [27]. The reason why the wound exudate in the control group is purulent is due to the presence of thick necrotic tissue.

In the immunohistochemistry result, compared to the control group who does not receive the application of veraGAV, the group that receives GAV showed a reduction of MMP-9. Our study corresponds with the previous study by Vijayalakshmi et al. (2012) that investigate the effect of aloe vera in peripheral blood mononuclear wound [15]. Their research showed that aloe vera can reduce the production of MMP-9. The mechanism involved in the reduction of the production of MMP-9 by gel AV is still unclear. Previous study suggested that down-regulation of MMP-9 might occur due to inhibition of the activation of NF- B and its subsequent binding to MMP-9 promoter or by inhibiting the production of prostaglandins (mediator) which induce MMP-9 expression [15].

Our study showed that GAV could reduce MMP-9. This study provides an important evidence in the use of GAV for wound treatment for patients. Previous study showed that two important factors that can impede healing in the diabetic wound are infection and excessive level of MMP-9. Study by Foote et al.(2017) already showed that GAV could reduce wound infection, including by Staphylococcus Aureus [6]. Based on the result of our study and another researcher, it can be suggested that veraGAV could be a good choice for wound treatment of fisherman in the coastal region.

\section{Conclusions}

This study is the first to study the role of the GAV in reducing MMP-9 in the diabetic wound. Our study showed that the use of GAV could reduce the level of the intensity of MMP-9 in the diabetic wound. Based on the result of this study, it can be suggested that GAV could be a good candidate for wound treatment for the fisherman in the coastal region.

\section{References}

1. NCD Risk Factor Collaboration, The Lancet 387,10027 (2016)

2. C.R.Rao, V.G. Kamath, A. Shetty, \& A.Kamath. Int J Diabetes Dev Ctries. 30, 80- 
85(2010)

3. Y. Zhao, E. M.Crimmins, P. Hu, Y. Shen, J. P Smith, J. Strauss, Y. Wang, Y Zhang. Int J Public Health. 61, 347-356 (2016)

4. Riskesdas. Kemenkes. 90 (2013)

5. K. B. Hobizal, D. K. Wukich. Diabetic Foot \& Ankle 3, 18409 (2012)

6. A. Foote, R. Henderson, A. Lindberg, C. Grigg, C.Greenfield, A.Kirke, K.Auret. Aust Fam Physician. 46, 923-927 (2017)

7. A.Banu, B. C. Sathyanarayana, G. Chattannavar. Australas Med J. 5, 305-309 (2012)

8. A.Surjushe, R.Vasani, D. G. Saple. Indian J Dermatol. 53, 163-166 (2008)

9. M. H. Radha, N. P. Laxmipriya. J Tradit Complement Med. 5, 21-26 (2015)

10. N.Takzare, M. Hosseini, G. Hasanzadeh, H. Mortazavi, A.Takzare, P. Habibi. Toxicol Mech Methods. 19, 73-77 (2009)

11. A.Oryan, A.Mohammadalipour, A. Moshiri, M. R. Tabandeh. Ann Plast Surg. 77, 37$46(2016)$

12. Y. Sari, I. Purnawan, D.W. Kurniawan, E. Sutrisna. Journal of Evidence-Based Integrative Medicine. 23

13. Y.Sari, I. Purnawan, E. Sutrisna, D. W. Kurniawan, Nasruddin, 3rd International Conference on Pharmacy and Pharmaceutical Science (Bali, 2018)

14. J. L. Lazaro, V. Izzo, S.Meaume, A. H. Davies, R.Lobmann, L. Uccioli. J Wound Care. 25, 277-287(2016)

15. D. Vijayalakshmi, R. Dhandapani, S. Jayaveni, P. S. Jithendra, C Rose, A. B Mandal. J Ethnopharmacol. 141, 542-546(2012)

16. S. M. Ayuk, H.Abrahamse, N. N. Houreld. T. J Diabetes Res. 2897656 (2016)

17. Y.Liu, D.Min, T Bolton, V. Nubé, S. M. Twigg, D. K.Yue, S. V. McLennan. Diabetes Care. 32, 117-119 (2009)

18. M. J.Reiss, Y. P.Han, E.Garcia, M Goldberg, Y. K Hong, W. L Garner. Surgery. 147, 295(2010)

19. J.B.Wright, K.Lam, A.G.Buret, , M.E. Olson, R.E. Burrell, Wound Repair Regen 10: 141-151(2002)

20. A. E. Rizzardi, A. T. Johnson, R. I.Vogel, S. E. Pambuccian, J.Henriksen, A. P. N Skubitz, G.C. Metzger Schmechel. Diagnostic Pathology. 7, 42 (2012)

21. H.Nagase, R.Visse, G. Murphy.Cardiovascular Research. 69, 562-573 (2006)

22. Y.Kudo, S. Iizuka, M.Yoshida, T. Tsunematsu, T. Kondo, A. Subarnbhesaj, T.Takata. J Biol Chem. 287, 38716-38729 (2012)

23. M. P Caley, V. L. C. Martins, E. A.O’Toole, Adv Wound Care, 4(4), 225-234 (2015)

24. K. Singh, K. Agrawal, N. K. Gupta, S. K. Mohan, G., S. Chaturvedi The International Journal of Lower Extremity Wounds. 13, 94-102 (2014)

25. J. J. Salazar, W. J. Ennis, T. J. Koh. J Diabetes Complications, 30, 746-752 (2016)

26. E. I Deryugina, E Zajac, A. Juncker-Jensen, T. A.Kupriyanova L, Welter, J. P. Quigley. Neoplasia (New York, N.Y.). 16, 771-788 (2014)

27. Y. Sari, G Nakagami, A Kinoshita, L Huang, K Ueda, S Iizaka, H.Sanada, J.Sugama. International Wound Journal. 5, 674-680 (2008) 